\title{
Immunocompatibility of Bacteriophages as Nanomedicines
}

\author{
Tranum Kaur, Nafiseh Nafissi, Olla Wasfi, Katlyn Sheldon, \\ Shawn Wettig, and Roderick Slavcev
}

School of Pharmacy, University of Waterloo, Health Sciences Campus, 10 Victoria Street South, Kitchener, ON, Canada N2L 3C4

Correspondence should be addressed to Roderick Slavcev, slavcev@uwaterloo.ca

Received 23 July 2011; Revised 15 January 2012; Accepted 24 January 2012

Academic Editor: Chunying Chen

Copyright ( $) 2012$ Tranum Kaur et al. This is an open access article distributed under the Creative Commons Attribution License, which permits unrestricted use, distribution, and reproduction in any medium, provided the original work is properly cited.

Bacteriophage-based medical research provides the opportunity to develop targeted nanomedicines with heightened efficiency and safety profiles. Filamentous phages also can and have been formulated as targeted drug-delivery nanomedicines, and phage may also serve as promising alternatives/complements to antibiotics. Over the past decade the use of phage for both the prophylaxis and the treatment of bacterial infection, has gained special significance in view of a dramatic rise in the prevalence of antibiotic resistance bacterial strains. Two potential medical applications of phages are the treatment of bacterial infections and their use as immunizing agents in diagnosis and monitoring patients with immunodeficiencies. Recently, phages have been employed as genedelivery vectors (phage nanomedicine), for nearly half a century as tools in genetic research, for about two decades as tools for the discovery of specific target-binding proteins and peptides, and for almost a decade as tools for vaccine development. As phage applications to human therapeutic development grow at an exponential rate, it will become essential to evaluate host immune responses to initial and repetitive challenges by therapeutic phage in order to develop phage therapies that offer suitable utility. This paper examines and discusses phage nanomedicine applications and the immunomodulatory effects of bacteriophage exposure and treatment modalities.

\section{Introduction}

Discovered independently by Frederick Twort and Félix d'Hérelle, respectively, in 1915 and 1917, bacteriophages are bacterial viruses that exist in two different life cycles and may or may not lyse their bacterial hosts as lytic and temperate bacteriophages, respectively [1-3]. While the ability of phage to attack bacteria has been known since their discovery, our knowledge about phage interactions with mammalian cells is very limited. Bacteriophages have been used clinically to treat human bacterial infections for about 80 years in the countries of the former Soviet Union and Eastern Europe [4]. Although historically their clinical use as antibacterials preceded that of antibiotics, both clinically and commercially, due to the advent of the "age of antibiotics" in the 1940s, phages were quickly declined as a therapeutic option. Despite their obvious efficacy in curing antibiotic-resistant infections, there are important caveats to their safe and efficient clinical application, and in consideration of these phage therapy is still at best considered an "experimental" treatment option.
The recent global increase in the emergence of multidrug-resistant (MDR) clinical strains of bacteria has led us to the precarious situation of entering a "post-antibiotic era" of untreatable infections and epidemics $[5,6]$. The systematic overuse of antibiotics by the medical and agricultural professions during the last century has precipitated a powerfully selective environment for MDR strains, resistant to even the most potent antibiotics available [6]. To further aggravate the situation, antibiotic research appears to have reached a dead end with even newer "last chance" modified molecules like linezolid and vancomycin now facing growing episodes of resistance and eventual inefficacy $[7,8]$. Moreover, only three new classes of antibiotics (lipopeptides, oxazolidinones, and streptogramins) have entered the medicine market in the last four decades all of which are indicated for the treatment of gram-positive $\left(\mathrm{G}^{+}\right)$bacterial infections [9].

Matsuzaki et al. [10] summarized the advantages of phage therapy over antibiotic therapy as follows: (i) it is effective against multidrug-resistant pathogenic bacteria; (ii) substitution of the normal microbial flora does not 
occur because the phage kills only the targeted pathogenic bacteria; (iii) it can respond quickly to the appearance of phage-resistant bacterial mutants because the frequency of phage mutation is significantly higher than that of bacteria; (iv) developing costs for a phage treatment are cheaper than that of new antibiotics; (v) side-effects of phage therapy are very rare compared to the antibiotic therapy $[10$, 11]. However, while phages as specific and self-replicating/ limiting antibacterials offer several advantages over antibiotics, their usage in mammals requires careful consideration and understanding of the host-mediated obstacles that challenge appropriate safety and efficacy as synergistic antibiotic cotherapeutics or replacements. Global fears now abound that the medical world may be thrust into conditions resembling the pre-antibiotic era and that procedures such as chemotherapy, wound control during surgery, and transplant immunosuppression are at risk yet again. These fears have rekindled the interest in the development of phage therapeutics to ensure long-term, efficient, safe, and harmless treatment options [12]. Phages have also been demonstrated to modulate immune system function. A primary example of this phenomenon includes the inhibition of both bacteria- and LPS-induced respiratory burst by human blood phagocytes [13]. It has also been suggested that phage may normalize cytokine production by blood cells isolated from patients [14], although this study was largely uncontrolled and further confirmation of this therapeutic bystander effect is warranted. Nonetheless, the increasing clinical and technological use of bacteriophages requires that all aspects of phage-mammal interactions be explored.

\section{Applications}

2.1. Phage Display. Tumor-targeting peptide display on phage surface is a direct and fast screening approach with promising results for targeting drugs into tumor cells [15]. Identification of ligand-receptor interaction in order to find the appropriate receptor on target cell facilitated by phage display technology play a crucial role in disease diagnosis, profiling, imaging, and therapy.

Advanced disease cell targeting relies on phage display technologies, in which polypeptides with desired binding profiles can be "serially selected, in a process called biopanning" [17]. Here, the heterologous peptide/protein coding gene is translationally fused to the bacteriophage capsid protein gene, where the resultant phages not only carry the gene encoding the displayed protein/peptide but are also capable of replication to amplify the construct (Figure 1). While phage display was traditionally employed to screen cDNA libraries, the application has more recently been applied to surmount some therapeutic gene delivery obstacles. This is achieved through the identification of highly specific and selective ligands that can deliver nanocarriers to the site of disease [16]. The combination of phage-display technology with nanocarrier-based drug-delivery systems is a novel approach toward creating more effective and safe therapies [15]. This approach is perhaps most suitably applied toward cancer therapy, in which the tumor-specific phage expressing peptides specific to a broad array of tumors are screened from billion phages by their specific affinity with uniquely expressed tumor receptors [18, 19]. Various studies demonstrate the successful application of isolated peptides for specific targeting and delivery of pharmaceutical nanocarriers, such as liposomes, to tumors. Wang et al. applied this protocol to prepare doxorubicin-loaded PEGylated liposomes modified with phage-panned proteins specific towards MCF-7 breast cancer cells and demonstrated that this strategy provides strong specific binding with target cells and increased cytotoxicity in vitro [15]. They proposed that the design and construction of novel nanomedicines targeted to a variety of cellular receptors is facilitated through selfassembly of selected phage proteins and "stealth" liposomes.

Recently, Bedi et al., demonstrated phage-targeted siRNA nanopharmaceuticals through their encapsulation into liposomes targeted to the breast tumor cells with preselected intact phage proteins [20]. "The presence of pVIII coat protein fused to a MCF-7 cell-targeting peptide "DMPGTVLP" in the liposomes was confirmed by Western blotting. This approach offers the potential for development of new anticancer siRNA-based targeted nanomedicines." On similar lines, Nicol et al. were able to devise a strategy for targeting the cardiac vasculature through the use of in vivo phage display to identify target peptides that are selective to the heart in two rat strains [21]. They hypothesized that, by cloning these peptides into the fiber protein of adenovirus, a potential targeted delivery system could be created. Interestingly, several peptides that are derived from phagedisplayed peptide library screening have been applied as new therapeutics in clinical trials, further validating phage-display targeted nanomedicine as a viable strategy that warrants further investigation and exploitation.

2.2. Phage Vaccine Technology. Kurzepa et al. first demonstrated that the injection of phage T7 into a mammalian host resulted in elevated interferon levels [22]. The potential application of bacteriophages as immunization tool was proposed since it was observed that the immune response was stimulated by the phage genome and not coat proteins. Interestingly, the isolated T7 genome did not show an interferon response suggesting that the phage coat protein ensures safe delivery of the genome in a form required to confer an immune response. As such, phage particles have been applied in DNA vaccine technology as a safe container for DNA delivery. The vaccine gene and its expression cassette are cloned into phage genome, and purified phage lysate can be directly injected into the host as a means of immunization [23]. Modified phage particles package their nucleic acid carrying the vaccine expressing sequence in their protein coat, likely protecting it from sources of degradation, before and after administration. Different small and large animal models have been vaccinated by phage DNA vaccines, and the results demonstrated a significantly higher and long-lasting antibody response compared to naked DNA vaccine or even purified recombinant protein [23-25]. Furthermore, as an exogenous antigen, the phage particle efficiently targets antigen-presenting cells (APCs), thereby stimulating a 


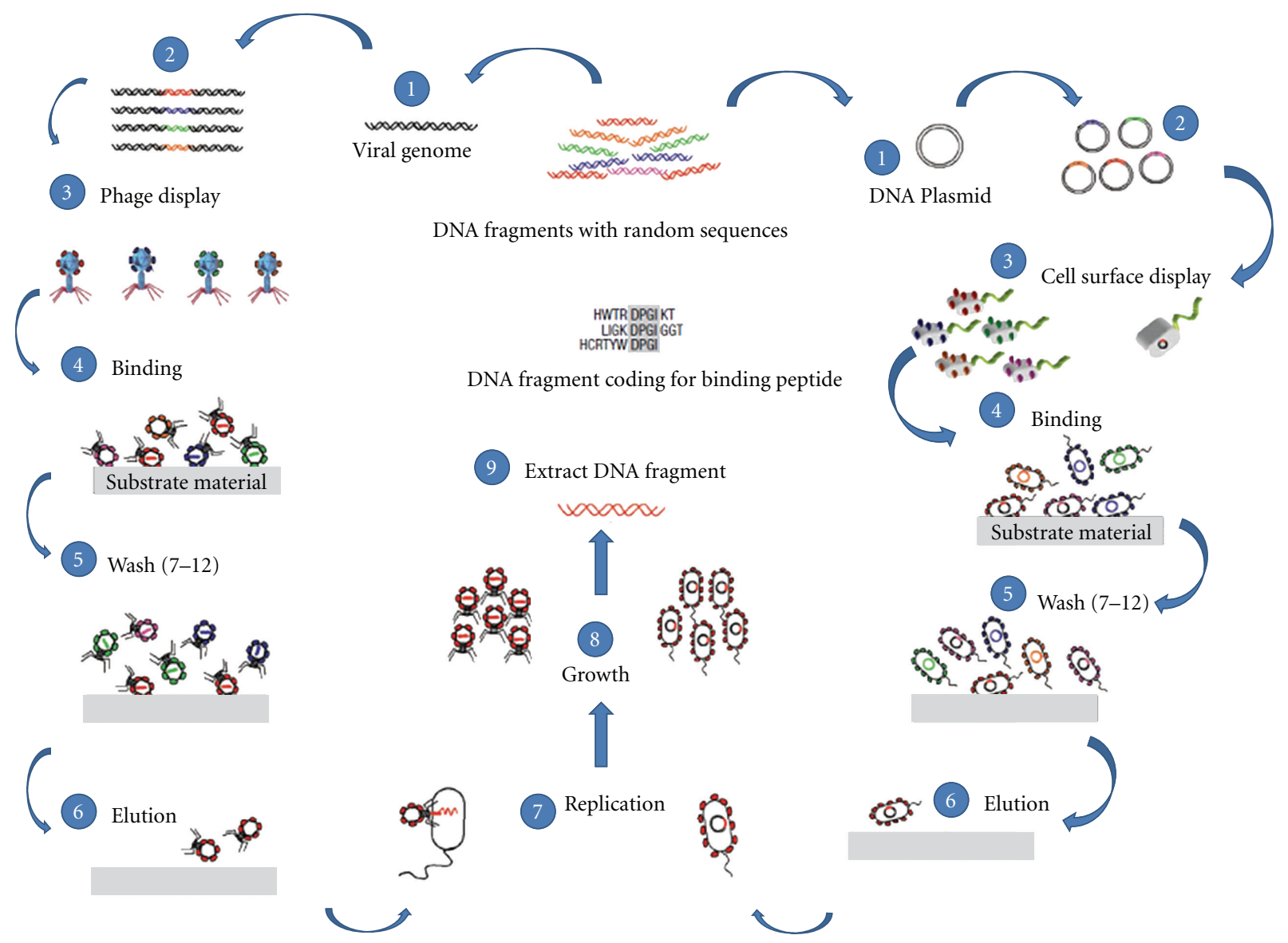

FIGURE 1: Phage display and cell surface display. Principles of the protocols used for selecting polypeptide sequences that have binding affinity to given inorganic substrates (Source: Nat Mater. 2003, 2(9):577-85.) [16].

superior specific humoral immune response to the vaccine [4], compared to standard "naked" DNA vaccine approaches.

Phage display as a new tool for developing modern vaccines demonstrates a unique application of bacteriophages in vaccine design and is influenced by the immunomodulatory effects of phage exposure (summarized in Table 1). The premise of phage-display vaccination exploits the capability of certain phages to display a specific antigenic peptide or protein on their surface via a translational fusion with capsid protein(s) [30]. Alternatively, phages displaying peptide libraries can be screened with a specific antiserum to isolate novel protective antigens or mimotopes-peptides that mimic the secondary structure and antigenic properties of a protective carbohydrate, protein, or lipid, despite possessing a different primary structure. Two different strategies have been defined for phage display: (1) translational fusion of antigen coding sequence to coat protein gene and (2) Artificial conjugation of antigen to the coat protein; both of which are robust and allow for a wide array of antigens to be displayed. In addition, since phage particles are themselves immunogenic, the antigen displayed on the phage is already combined with a natural adjuvant, which eliminate the necessity of alternative adjuvant protein purification and further conjugation with the vaccine [31]. This fact dramatically reduces the cost for generating new vaccines while enhancing efficiency. In addition, since phages are unable to replicate and in eukaryotic cells in the absence of a suitable prokaryotic host, these therapeutics behave as inert particulate antigens [23]. In recent years, work has shown that whole phage particles can be applied to deliver vaccine expression cassette cloned into their genome or express antigens on their surface. The combination of the above two promising technologies may result in "hybrid phages" to create inexpensive, easily manipulated, and rapid production cocktail vaccines [4].

\subsection{Phage-Phagocyte Interactions in Antitumor Therapies.} Bacteriophages and their demonstrated ability to influence mammalian immune systems have also been exploited to develop novel microbial strategies versus cancer development. Bloch first suggested that phage may possess anticancer activity and was able to demonstrate preferential accumulation of phages in cancer tissue and subsequent inhibition of tumor growth [32]. This was also confirmed by Kantoch and Mordarski in 1958 [33] and in studies done subsequently by Dabrowska et al. in 2004, 2005, and 2007 [26, 34-36]. The models of the studies were the wild-type bacteriophage T4 and its substrain HAP1 (with enhanced affinity for melanoma cells), a pentameric protein occurring 
TABLE 1: Immunomodulatory effects of bacteriophage exposure.

\begin{tabular}{|c|c|c|}
\hline Phage interactions & Immunomodulatory effects & Reference \\
\hline \multirow[t]{2}{*}{$\begin{array}{l}\text { Phage-phagocyte interactions in } \\
\text { antitumor therapies }\end{array}$} & $\begin{array}{l}\text { Phages expressing Fab fragment specific for tumor accumulated in } \\
\text { the tumor tissue and induced humoral and cellular immune } \\
\text { responses, leading to solid tumor regression in mice. }\end{array}$ & {$[22]$} \\
\hline & $\begin{array}{l}\text { T4 phages interacting with B3 integrins modulated the function of } \\
\text { human T cells and platelets. Bone marrow dendritic cells did not } \\
\text { confer similar results, but a significant delay in tumor growth was } \\
\text { observed. }\end{array}$ & {$[26,27]$} \\
\hline Antiphage immune response & $\begin{array}{l}\text { As foreign exogenous antigens, phages induce strong antiphage } \\
\text { humoral responses resulting in rapid and efficient neutralization and } \\
\text { clearance upon subsequent exposure. Phages circulating in the blood } \\
\text { were inactivated by macrophages of the RES in synergy with } \\
\text { antiphage antibodies-an outcome that would quickly diminish the } \\
\text { efficacy of phage therapy upon subsequent exposures. Repeated use of } \\
\text { a phage as a therapeutic, in addition to the interactions with the } \\
\text { innate immune system, would result in the stimulation of memory } \\
\text { cells, clone amplification, and subsequent antibody production. } \\
\text { Phage mutagenesis followed by repeated administration of phage } \\
\text { therapy and selection for long-circulating phage is an elegant method } \\
\text { that permitted investigators to select and isolate mutant phage that } \\
\text { persevere from the blood of a mouse. }\end{array}$ & $\begin{array}{l}{[22,28,} \\
29]\end{array}$ \\
\hline $\begin{array}{l}\text { Bacteriophages and Reactive Oxygen } \\
\text { Species Production }\end{array}$ & $\begin{array}{l}\text { Phage-mediated inhibition of ROS production by phagocytes is an } \\
\text { important phenomenon contributing to the beneficial effects of } \\
\text { phage therapy in patients with sepsis, a clinical setting where } \\
\text { excessive production of ROS appears to play an important role, and } \\
\text { agents interfering with ROS have been advocated for treatment. }\end{array}$ & {$[22]$} \\
\hline
\end{tabular}

on the phage heads. Phages significantly inhibited lung metastasis of B16 melanoma cells (T4 by $47 \%$ and HAP1 by $80 \%)$. The potential ability of $\beta 3$ integrins on the surfaces of some (including cancer) cells to bind the KGD (Lys-Gly-Asp) motif of phage protein 24 was proposed. Further, it seems that by occupying the $\alpha \mathrm{v} \beta 3$ integrin receptor, phages could deprive neoplastic cells from growth signals provided by extracellular matrix proteins. In addition, studies confirmed that blocking $\beta 3$ integrins by ligand analogs inhibits the binding of phages to cancer cells, which seems to confirm the hypothesis. Binding to mammalian cells by phage may also be achieved via nonintegrin receptors. For example, it has been suggested that CD26 is closely involved in HIV cell entry [37]. Importantly, the slower growth was only observed if purified phage preparations were applied. Raw phage lysates, containing numerous bacterial debris, for example, a high LPS concentration, induced a large acceleration of tumor development [26]. Moreover, oral application of a bacteriophage preparation is safer and at least as effective as i.p. [35]. After their studies on binding to cancer cells in vitro and attenuating tumour growth and metastases in vivo, Dabrowska et al. described a nonsense mutation in the hoc gene that differentiates bacteriophage HAP1 and its parental strain T4. In this study, the antimetastatic activity of the T2 phage, which does not express protein Hoc, with those of T4 and HAP1 was compared in the B16 melanoma lung colonies and found that HAP1 and T2 decreased metastases with equal effect, more strongly than did T4 [36]. The increased antitumor activity of HAP1 may be related to the fact that this phage has a damaged Hoc protein, a protein which symmetrically protrudes from the capsid. Removal of this steric barrier and the free exposition of KGD ligand may be the reason for the stronger inhibition of metastasis. Later, Eriksson et al. described the inhibition of tumor growth by tumor-specific phages, which induced the infiltration of polymorphonuclear leukocytes (PMNs) and the secretion of IL-12 (p70) and interferon $\gamma$. Hence, bacteriophages are able to induce expression of cytokines which could alter the immunosuppressive tumor microenvironment and potentiate neutrophil-mediated tumor destruction [38]. Phage specificity to the tumor confers a more localized immune response at the target cell. This is extremely important to maximize the safety of anticancer treatments considering the devastating side effects of other options like chemotherapy on nontumor tissues in patients undergoing cancer therapy. Regardless of the mechanisms of action, the involvement of phages in oncology seems very promising.

\subsection{Bacteriophages and Reactive Oxygen Species Production.} Aerobic organisms require oxygen for the oxidation of nutrients and energy generation, where in this process different waste and byproducts are inevitably produced. Although oxygen is essential for all aerobic organisms, its reactive metabolites are highly toxic to all organisms. Reactive oxygen species (ROS) interact with a variety of cellular components, including proteins, lipids, and nucleic acids. ROS are believed to be responsible for the initiation as well as the progression of cancer. The microenvironment of cancer cells shows high level of oxidative stress, which promotes cell proliferation and stimulates tumor progression [39]. In addition, ROS are employed by neutrophils and mononuclear phagocytes to 
neutralize endocytosed antigenic material. However, intensified production of ROS molecules may devastate the body's endogenous antioxidant defense mechanisms, and lead to oxidative stress, which are involved in causing many different disorders mainly result in serious tissue damage [40], or induce immune cells apoptosis depending on the severity of oxidative damage. Therefore, ROS-suppressive effects may be beneficial in controlling many different adverse effects. Some studies support the possible interactions between phages and mammalian cells by providing evidence of inhibition of ROS formation by bacteriophages. In fact, antibiotic therapy of Gram-negative bacteria leads to excessive release of bacterial lipopolysaccharide (LPS), and LPS may in turn activate neutrophils to produce ROS. It was demonstrated that bacteriophages are capable of reducing the production of ROS by phagocytes in the presence of bacteria. The mechanism of action appears quite complex as phages alone do not impart this phenotype, but rather involves not only phagephagocyte interaction but also phage-LPS interaction and bacterial lysis [41]. Some phages recognize and bind LPS that serves as their natural bacterial receptor [42]. Phagemediated inhibition of ROS production by phagocytes may be a very important phenomenon contributing to the beneficial effects of phage therapy in patients with sepsis [43], a clinical setting where excessive production of ROS appears to play an important role and agents interfering with ROS have been advocated for treatment [44].

2.5. Phage Lysins as Antimicrobials. Bacteriophages have been used in East Europe and the Former Soviet Union to treat bacterial infections even after the advent and global use of antibiotics, which saw this alternative treatment option fading in western countries. However, over the past two decades with the global spread of antibiotic-resistant infections, research interests in the West have once again turned to alternative treatment modalities. While a plethora of evidence exists confirming the effectiveness of the application of intact phage particles to treat specific bacterial infections, recent advances in molecular biology now also allowed for the development of novel phage-derived enzymes, such as lysins [45]. Bacteria-phage coevolution has yielded phage endolysins encoded by ds DNA phage that specifically lyse their host bacterial cell by hydrolysing one of the four major bonds in the peptidoglycan layer that forms the bacterial cell wall. The majority of studies to date demonstrate that these are modular enzymes with lytic domains that preserve their parental specificities when fused. Endolysins are composed of at least two distinctly separate functional domains: a C-terminal cell-wall binding domain, which directs the enzyme to its target, and an $\mathrm{N}$-terminal catalytic domain that is comprised of one or more of the following types of peptidoglycan hydrolases: endopeptidases, muramidases (lysozyme), N-acetylmuramoyl- L-alanine amidases, and glucosamidases [46]. Phage endolysins are particularly effective against gram-positive bacterial pathogens with an exposed cell wall, whereby the purified endolysin can lyse the cell from without. Purified endolysins are now extensively used not only in the food industry primarily to combat against Listeria monocytogenes contamination [47] but also in medical setting, primarily against streptococcal and staphylococcal species. Pal amidase encoded by pneumococcal bacteriophage Dp-1 [48], PlyC from the streptococcal, and Cpl-1 encoded by the pneumococcal phage Cp-1 have been shown to be effective antimicrobial agents against Streptococcus pneumoniae [49]. Furthermore, phage EFAP-1-derived EFAL-1 endolysin has been shown to rapidly and potently lyse antibioticsresistant enterococcal strains to control "disease-causing Enterococcus spp." [49]. One particular endolysin of interest in our research group is staphylococcal phage-K-derived endolysin, LysK which can be considered as perspective antimicrobial agent against Staphylococcus aureus (S. aureus). LysK is a monomeric 495 amino acid protein, was first isolated in 2005, and it has been shown to be active against a broad spectrum of staphylococci including those of the most medical importance such as methicillin-resistant $S$. aureus (MRSA) and vancomycin-resistant S. aureus (VRSA) [50]. More recent studies of this lysin are focused primarily on its enzymatic properties [51]. This is of great importance in determining the optimal conditions of use as well as for future storage.

Recently, it has been shown that a newly developed chimeric endolysin called ClyS once purified is active against MRSA, vancomycin intermediate (VISA), and methicillinsensitive (MSSA) strains of $S$. aureus in vitro. In addition, this lysin also proved to have synergistic interactions with both vancomycin and oxacillin in vitro and have synergistic protection of septic death in vivo against MRSA [52]. The in vivo mouse studies were also promising where a nasal decolonization model demonstrated a 2-log reduction in viability of MRSA cells one hour following a single treatment with ClyS and one IP dose of ClyS also protected against death by MRSA in a mouse septicemia model [53]. Very similar results were reported on novel phage-derived enzyme "cysteine-histidine amino peptidase" with excellent antistaphylococcal properties [54]. From these results additional treatment options have been suggested which combine antibiotic and phage therapy to fight against multi-drug resistant bacterial infections. However, most of the research and development of phage lysine technologies has been performed in a small scale, resulting in very few commercially available products to date. In fact, the true value of phage-derived antimicrobial agents will be unambiguously realized once these products enter into broad clinical application and commercial availability [45].

\section{Immune Responses}

It can be expected that humans have been exposed to several species of phage which begins shortly after birth, particularly those specific for human natural flora. The ongoing microbiome project has revealed that bacteria in our gut, skin, and other body cavities outnumber our human cells by a factor of at least $100[55,56]$. The bacterial symbionts are likely to maintain their presence despite the dynamics of the intestine and the host immune system through their interaction with the mucus gel layer overlying the intestinal epithelium as well as a process for obtaining host tolerance [57]. Like eukaryotic 
viruses, phages are nucleoproteinaceous in composition, comprised of a nucleic acid genome and encased within a protein coat and in some cases lipids within their capsids or even capsid envelopes. These proteins and DNA are recognized by mammalian hosts as foreign antigens, and as such phages stimulate an immune response that subjects them to neutralization and clearance by the host immune system [58]. The use of phage in the construction of elegant new therapeutics such as targeted gene delivery vehicles, anticancer agents, scFv carriers, and other clinical applications also requires the consideration of phage immunogenicity and circulation longevity in developing efficacious biologics [55-57]. In addition, there is a limited understanding and lack of data focusing on phage pharmacokinetics (PK) and pharmacodynamics [59], although some important effort has been lent toward modeling phage absorption, distribution, metabolism, and excretion (ADME) profiles [60]. Table 2 describes the advantages and disadvantages of using phage as nanomedicine in various fields. Many questions around the capabilities of phage to get into the circulatory system of higher organisms still remain as this determines the potential phage activity in nanomedicine and antibacterial treatment and will be addressed here [61]. This paper will focus mainly on host-mediated responses to phage therapy, discussing current knowledge of immunomodulatory effects of bacteriophage exposure and treatment modalities.

3.1. Antiphage Innate Immunity. The issue of bacteriophage interactions with the mammalian immune system and its components is still not precisely defined. Phages entering eukaryotic hosts are highly immunogenic foreign antigens that can interact with the innate immune system to induce specific humoral as well as cellular immune responses [65]. Evidence increasingly suggests that phages influence mammalian immune responses, including the attenuation of specific and nonspecific immune reactions, and maintenance of local immune tolerance to gut microorganism-derived antigens. Phage preparations administered orally may down regulate the antigen-processing abilities of intestinal dendritic cells, whereas phages administered intravenously are rapidly phagocytosed by liver cells [66]. Soluble CD14 and LPSbinding protein are major serum factors with the ability to bind pathogens and initiate innate immune responses. Although innate immunity cannot be entirely separated from its adaptive counterpart, for the purpose of clarity, we will also discuss antiphage immunity according to the mechanism(s) of neutralization and clearance.

\subsubsection{Phage-Specific Innate Cellular Immune Responses}

Pathogen-Associated Molecular Patterns (PAMPs). Host cells express pattern recognition receptors (PRRs) that sense pathogen-associated molecular patterns (PAMPs). PAMPs can also be recognized by a series of soluble pattern-recognition receptors in the blood that function as opsonins and can initiate the complement pathways. Most body defense cells have pattern-recognition receptors for these common PAMPS, and so there is an immediate response against the invading microorganism/phage. The best-characterized pattern-recognition receptors are Toll-like receptors (TLRs) [67-69], so named due to their homology to the Toll receptors, first discovered in Drosophila. TLR-2 was originally described to recognize LPS, a major constituent of the outer membrane of Gram-negative $\left(\mathrm{G}^{-}\right)$bacteria, whereas later studies have identified TLR-4 as the central transmembrane component of the LPS receptor [70, 71]. TLR9 was first shown to recognize deoxycytidylate-phosphatedeoxyguanylate $(\mathrm{CpG})$ regions in bacterial DNA and is now known to be important in defending against different viral and parasitic pathogens [72]. Abundant portions of unmethylated $\mathrm{CpG}$ dinucleotides (CpG motifs) that are found in prokaryotic (primarily bacterial) genomes as well as synthetic oligonucleotides $[72,73]$ containing CpG motifs have in recent years been shown to activate the innate immune system and can elicit a Th1-dominated response, resulting in release of a wide range of cytokines (IFN- $\gamma$, IL-2, IL-6, IL-18, and TNF- $\alpha$ ) [74-76]. This discovery has opened door for research into the use of $\mathrm{CpG}$ motifs for the use as a powerful adjuvant for DNA vaccines and/or immunomodulatory agents not only to direct an adaptive long-lived immune response against pathogenic agents, but also to prevent unwanted Th2 humoral immune responses [76]. Moreover, CpG DNA also has the unique property of being able to connect the innate and adaptive immune responses through its ability to activate antigen-presenting cells (APCs). Macrophages, dendritic cells, and epithelial cells have a set of transmembrane receptors that recognize different types of PAMPs, which in turn lead to the expression of various cytokine genes (IL-12 which stimulates the production of Th1 cells, IL-23, which stimulates the production of Th17 cells, and IL-6) [68].

It is also known that the time of clearance (degradation/elimination) of bacteriophages in mammalian organisms depends on their surface protein properties [77]. Assuming that phage structural surface proteins are responsible for their recognition as foreign antigens and rapid clearance by the reticuloendothelial system (RES), attenuation of immunogenicity should thus be possible via alterations to these surface antigens. Employing this logic, Merril et al. devised an elegant strategy to decrease phage immunogenicity and increase the persistence of phages P22 and $\lambda$ within mice [78]. This since patented system consists of growing phages on a mutator $E$. coli strain then serially passaging them through mice 10 times, each time selecting for residual phage that persist for several hours. This technique led to their isolation of $\lambda$ capsid mutants that persisted for more than 18 hours [78]. Mutation(s) conferring RES evasion and prolonged persistence within the mouse were mapped to the $\lambda E$ gene, a mono-hexameric major capsid protein. The success of this technique not only opens the door to the application of phage as longer-lasting, circulating biologics; but more fundamentally also strongly suggests that evasion of the RES through a single point mutation must mitigate clearance through a specific immunity mechanism; likely the prevention of opsonization and/or highly efficient antibody-mediated endocytosis. However, this technique has not been tested to retain function in 
TABLE 2: Advantages and disadvantages of phages as nanomedicines.

\begin{tabular}{|c|c|c|c|}
\hline $\begin{array}{l}\text { Phage nanomedicine } \\
\text { platform }\end{array}$ & Advantages & Disadvantages & Reference \\
\hline $\begin{array}{l}\text { Filamentous phages } \\
\text { as drug-delivery } \\
\text { platform }\end{array}$ & $\begin{array}{l}\text { Targeted drug-conjugated filamentous phage } \\
\text { nanoparticles are unique antibody-drug } \\
\text { conjugates and they have been shown to inhibit } \\
\text { target cells in vitro with a potentiation factor of } \\
1000 \text {-fold over the corresponding free drug in one } \\
\text { study. }\end{array}$ & $\begin{array}{l}\text { The pharmacokinetics, the biodistribution, } \\
\text { and the immunogenicity of conjugated phages } \\
\text { are still under study. Repeated administration } \\
\text { of phage results in amplified immune response } \\
\text { and rapid neutralization and clearance of the } \\
\text { phage. }\end{array}$ & {$[62]$} \\
\hline
\end{tabular}

Phages are effective against multidrug-resistant pathogenic bacteria; phage specificity prevents damage to original microflora; phages respond quickly to the appearance of resistant bacterial mutants; phages offer low scale-up costs; phages

Phage as antibacterial side effects are very rare compared to the nanomedicines antibiotic therapy. Due to the different mechanism of bactericidal action phage provide the opportunity for combined approaches with antibiotics improving antibacterial potency in some cases by up to $2 \times 10^{4}$-fold higher than antibiotic alone.

Bacterial cells may similarly build resistance against phage infection. Other barriers to infection include restriction or exclusion systems that block propagation. Phage may horizontally transfer toxicity between hosts via generalized or specialized transduction. Some of these barriers may be overcome by using a cocktail strategy, phage incapable of transduction, or genetic modification.
Phages not only provide the basis to pan for potential peptides that bind a specific receptor but also can serve as a targeting nanomedicine platform to shuttle drugs and/or genes, or to specific cells, or modulate the activity of these receptors.

Landscape phage-based approach has decreased drawbacks compared to the chemical modified nanocarriers with cancer-selective peptides.
Potential for phage to confer immunogenicity against self antigens that are presented on surface of phage if similar to that found in the mammalian host.

Localized targeting of tumour cells may not be sufficient for some phage-based antitumour strategies. peptide as a targeted nanomedicine human subjects. Consistent with this, Molenaar et al. have shown that the specificity and delivery efficiency of the filamentous M13 phage into parenchymal and Kupffer cells of the liver with the incorporation of targeting ligands [29]. In their study they investigated the pharmacokinetics and processing of native and receptor-targeted phage in mice. Sradiolabeled M13 was chemically modified by conjugation of either galactose (lacM13) or succinic acid groups (sucM13) to the coat protein of the phage to stimulate uptake by galactose recognizing hepatic receptors and scavenger receptors, respectively. Receptor-mediated endocytosis of modified phage reduced the plasma half-life of native M13 $(t(1 / 2)=4.5 \mathrm{~h})$ to $18 \mathrm{~min}$ for lactosylated and $1.5 \mathrm{~min}$ for succinylated bacteriophage. Internalization of sucM13 was complete within $30 \mathrm{~min}$ after injection and resulted in up to 5000 -fold reduction of bioactive phage within $90 \mathrm{~min}$.

Phagocytes/Macrophages. The ability of bacteriophages to reduce ROS production by polymorphonuclear leukocytes (PMNs) in the presence of bacteria or their endotoxins has been recently confirmed [43]. It has been shown that a purified T4 phage preparation with low-endotoxin content could significantly diminish the luminol-dependent chemiluminescence of peripheral blood polymorphonuclear leukocytes stimulated by lipopolysaccharide $[43,70]$. It was suggested that phage-mediated inhibition of LPS- or bacteria-stimulated ROS production by PMNs may be attributed not only to phage-PMNs interactions but also to
phage-LPS interactions and bacterial lysis [43]. Although the mechanism of phage inactivation by PMNs is not clearly understood, the involvement of hypochloric acid, a highly reactive metabolite generated during PMN stimulation, is likely involved. Hypocholoric acid likely imparts damage to the nucleic acids and capsid proteins alike, resulting in viral neutralization [31]. Decades earlier, Inchley [79] reported that T4 was almost completely cleared from mice by PMNs within 30 minutes of injection, and similar results of phage clearance have also demonstrated for T2, $\varphi \mathrm{X} 174, \lambda$, and P22 [78, 80, 81]. While the RES is capable of rapid phage clearance, particularly in the thymus and the liver, significant titers of infective phage have also been rescued from the mouse spleen several days following inoculation, irrespective of the route of immunization [77, 79]. The relatively poor phagocytic activity of splenic macrophages may serve to preserve phage, allowing efficient viral sampling by B cells. The macrophage is critical component of innate immunity and front-line response against tissue invasion. Once activated, macrophages produce an assortment of microbicidal effectors and immunoregulatory cytokines that act to eliminate the invasion agent and influence the course of ensuing cognate immune response. The RES is comprised of pinocytic reticular and endothelial cells, and phagocytic monocytes and macrophages, and while pinocytosis may play a negligible role in RES clearance of phage, phagocytic cells account for rapid and significant removal of administered phage. Kupffer cells (specialized liver mononuclear 
phagocytes) were shown to be the primary cells responsible for this activity in mice [79]. Bacteriophages applied intravenously (i.v.) to mice accumulated mainly in the liver at a rate 12 times greater than that seen in the spleen, but phage titers decreased much faster than those in other organs. Splenic macrophages also clear bacteriophages, but the action of these cells on phage clearance and degradation has been shown to be four times lower than that of the Kupffer cells [79]. Nelstrop et al. demonstrated that "immune" macrophages, obtained by laparotomy after prior immunization of rabbit by the investigated phage T1, inactivated bacteriophages faster than "nonimmune" ones. Furthermore, they showed that macrophages are capable of cellular immunity with no involvement of humoral factors, whereby clearance of phages was observed with no simultaneous detection of produced antibodies [82]. In naive, germ-free mice that had never been previously exposed to bacteria or bacteriophages (as such possessing no antibodies that could confound results), bacteriophages were shown to be rapidly cleared by the spleen, liver, and other filtering organs of the RES $[6,83]$.

Dendritic Cells. Apart from the above-mentioned key players of innate cellular immunity, dendritic cells (DCs) play a key role in the initiation of the immune response, mainly by priming T-cell- and antibody-mediated adaptive immunity [84]. The immunological activity of dendritic cells has been investigated for many years, and although in vivo experiments have demonstrated the phagocytic activity of these cells, verification of these observations in vitro has been difficultly proven. The endocytosis of latex microspheres by dendritic cells was probably the first convincing proof of the phagocytic abilities of these cells observed outside a living organism, and, unlike artificial particles, phagocytosis of bacteriophage T4 by dendritic cells appears to be far stronger [85]. Electron microscope images showed an agglomeration of viral particles around dendritic cells. Moreover, the phages seemed to be trapped in phagolysosomes and devoid of their outer coat during phagocytosis [85]. It has been demonstrated that DCs could affect host immune priming after both oral and i.v. phage administration. These cells prime $\mathrm{T}$ cells, for example, for IFN-gamma production, and they are applied as an adjuvant in antitumor therapies. DCs were shown to increase their antitumor action when stimulated by purified T4 phage preparations. In addition, it was demonstrated that in vitro interaction between $\mathrm{T} 4$ phages and bone-marrow-derived dendritic cells (BM-DCs) followed by tumor antigen activation modifies the immune response in tumor-bearing mice and leads to a significant delay in MC38 mouse colon carcinoma growth [65]. It is suggested that pretreatment of DCs with phages can be considered as beneficial and a novel strategy in antitumor immunotherapy.

\subsubsection{Phage-Mediated Innate Humoral Immune Responses.} Through the use of a T7-phage peptide display library, Sokoloff et al. found a correlation between the peptides displayed and survival of the phage in rat circulatory system. They noted that, in rat blood, peptides with carboxyterminal lysine or arginine residues protected the phage against complement-mediated inactivation by binding C-reactive protein [86]. In contrast, phages resistant to inactivation in human serum were instead found to display Cterminal tyrosine residues. Unlike in rats, C-reactive protein is not elevated in humans [87], and the protective protein was suspected to be $\alpha 2$-macroglobulin. Kim et al. were the first to claim in their published research article that PEGylation can increase survival of infective phage by delaying immune responses and indicating that this approach can increase the efficacy of bacteriophage therapy. Their results show that PEGylation of phages can reduce cellular immune response such as antigen-specific T-cell proliferation, decreasing release of associated cytokines. In their work on both naïve and immunized mice, PEGylated Felix-O1 phage (i) decreased induction of Th1-associated cytokines such as IFN- $\gamma$ and other cytokines such as IL-6, (ii) lowered splenocyte proliferation, which would be expected to support longer survival of modified phage particles, and did not affect phage stability [88]. Compared with the survival increases seen with the PEGylated phages, the increases in antigenspecific IgG production upon the second challenge with native phage were only marginal. In addition, no significant difference in survival of PEGylated or native Felix-O1 in immunized mice was found. It is suggested that more modification on the available PEGylation chemistry may improve the blood circulation in pre-immunized animals [89].

3.2. Antiphage Adaptive Immunity. A large portion of what we know to be adaptive immunity concerns the activation of complex pathways, more specifically those that are activated by the innate system and are memory dependent. In most cases $\mathrm{T}$ and $\mathrm{B}$ cells of the adaptive branch of immunity ultimately clear pathogens from the body and provide longlived memory cells to prevent further activation or damage [90]. The activation of the complement cascade by cell surface recognition proteins or by secreted antibody results in the release complement cleavage products that interact with a wide range of cell surface receptors found on myeloid, lymphoid, and stromal cells. This intricate interaction among complement activation products and cell surface receptors provides a basis for the regulation of both B- and T-cell responses [91]. Three potential ways that the complement system can be activated prior to an acquired response by nonclonal means are the alternative pathway which recognizes surfaces lacking certain carbohydrates that are common to eukaryotic organisms, the classical pathway, which can be triggered by low-affinity "polyspecific" or cross-reactive IgM antibodies binding to repetitive epitopes that bacterial and viral surfaces characteristically present, and a pathway that is initiated by mannan-binding lectin [92]. A central protein of the complement system that provides a link between innate and adaptive immunity is $\mathrm{C} 3$, which is critical to immune defense. The above three pathways of complement activation converge at the activation of $\mathrm{C} 3$ yielding a diverse set of biological responses [93]. As foreign exogenous antigens, the administration of phage will generally induce a strong antiphage humoral response. Phage endocytosis by specialized antigen-presenting cells (APCs), whereby 
immunogenic epitopes are presented to antigen-specific T-helper cells, will result in the formation of memory cells following primary immunization. This confers rapid and efficient neutralization and clearance of the antigen upon subsequent exposure. Bacteriophages circulating in the blood are inactivated by macrophages of the RES in synergy with antiphage antibodies-an outcome that would quickly diminish the efficacy of bacteriophage therapy upon subsequent exposures [28]. Repeated use of a phage as a therapeutic, in addition to the interactions with the innate immune system, would stimulate memory cells and result in the production of antibodies. Such activation of the adaptive immune system relies on somatic mutations and clonal expansion of $\mathrm{T}$ and $\mathrm{B}$ cells, which can take at least three to five days. Immunization with bacteriophage phiX174 has been used extensively to diagnose and monitor primary and secondary immunodeficiencies $[62,94]$. Patients with a variety of conditions, including T-cell or T/B-cell interaction dysfunctions such as adenosine deaminase deficiency [95], X-linked immunodeficiency with hyper IgM and CD40 ligand deficiency [96], major histocompatibility complex class II deficiency [97], and HIV disease itself $[98,99]$ have been evaluated with this method. Patient immune responses to bacteriophage phiX174 immunization with T-cell or T/B-cell interaction deficiencies are characterized by abated or absent antibody titers after repeated immunizations as well as limited immunoglobulin isotype switching from IgM to IgG. In normal individuals injected with the highly immunogenic phage phiX174, the phage is normally cleared within three days and a primary immunoglobulin $\mathrm{M}$ response can be observed that peaks two weeks after the initial injection or immunization [100]. If another injection is made six weeks later, the $\operatorname{IgM}$ and IgG antibody titers increase and peak within one week of the second injection; subsequent phage injections result in further increases in the IgG titers. However, no detectable antibody response to phage, even after repeated injections was seen in patients with severe combined immune deficiency (SCID), which is characterized by the absence of both $\mathrm{B}$ and $\mathrm{T}$ cell functions. These patients also had prolonged phage circulation period [83]. Further, bacteriophage phiX174 immunization has been used to measure CD4 T cell function in vivo in human immunodeficiency virus (HIV)-infected patients across all disease stages and phiX174 immunization seems to be a useful tool for measuring immune function in vivo [101]. In this study, function was evaluated by measuring the ability of $\mathrm{T}$ cells to provide help to B cells in antibody production, amplification, and isotype switching. In vivo humoral responses to phage phiX174 have been used for more than 30 years in clinical immunology as a measure of $\mathrm{T}$ helper cell-dependent antibody production $[73,101,102]$.

Interestingly, phage immunological responses may vary, in particular with respect to prior infection with host strains of bacteria. In patients with acute staphylococcal infection, antiphage antibody titer was reported to arise very strongly. The titers were particularly elevated during infections: a fourfold rise was observed within 6-14 days of acute staphylococcal infections, whereas a fall in the titer correlated with treatment and was usually slow and followed the clinical regression of the infection $[103,104]$. Synnott et al. explored the possibility of oral administration of a recombinant $\mathrm{T} 2$ bacteriophage oral vaccine against Salmonella typhimurium in mice, where they fused segments of the Salmonella flagellin proteins FliC and FljB to the $\mathrm{N}$ terminal of the T2 SOC (small outer capsid protein) [105]. Over a 14-day period BALB/C mice were orally administered twice daily, either purified recombinant protein or fused $\mathrm{T} 2$ protein, then monitored for anti-FliCm or anti-FlijBm IgA production. No significant response was seen until day 33 , with concentrations peaking 47 days after the initial administration and subsiding after 61 days. While they noted that 465 times less protein was displayed by the phage as compared to the recombinant protein dose, the degree of immune response was similar. This finding suggests that phage display increases the immunogenicity of the displayed protein, and in fact the phage particle could act as an adjuvant in clinical trials [105]. However, the mechanism by which a peptide displayed on a phage particle produces a greater immune response than a greater quantity of the same peptide in free form requires further investigation. In addition, there was a large variation between individual mice in a given group, with some showing no response at all. Mice administered with recombinant protein in particular showed a large disparity between three mice with no reaction, one with a moderate reaction, and one that had a huge reaction in this recent study and therefore requires verification from further studies.

3.3. Factors Affecting Phage Immune Responses. The nature of an immune response versus the formation of phage antigens is influenced by number of factors: (1) the physicochemical properties of the phage including the size and number of different surface epitopes, (2) the route of immunization; some routes tend to impart active immunity, while others confer tolerance, (3) the dose of phage administered; low doses of antigen have been shown to stimulate cell-mediated Th1 cytokine profiles while higher doses stimulate the Th2 pathway, (4) patient history of exposure; primary antibody response to phage in naive individuals would be much less efficient in clearing phage antigens than secondary exposure in primed individuals due to B-cell maturation, isotype switching, and affinity maturation; and (5) antibody and cytokine profile of-different isotypes impart different functions.

Given the intimate relation bacterial strains and their phage have with human, the large number of unstudied phage strains that are associated with the human microbiome and, in light of the recent studies, the available concerning phage interactions with animals and humans are still very limited and need further investigations for their advancing use as nanomedicine and as phage therapy.

\section{Conclusion}

Phage has come a long way since first being applied as antibacterials and is being revisited as with a serious eye in light of the upsurge of multi-drug-resistant clinical strains. 
These versatile and malleable entities are further being engineered into new exciting phage-based therapeutics such as targeted gene-delivery vehicles and as anticancer agents. However, their usage in mammals requires careful consideration and understanding of the host-specific immune response when being applied as synergistic antibiotic cotherapeutics or replacements. Phage can and do interact with mammalian innate immunity to elicit specific humoral and cellular immune responses. Although efficient clearance of phage may be primarily mediated by the RES of innate immunity, adaptive responses to phage immunizations cannot be underestimated. Depending upon the phage display and structural surface proteins, attenuation of immunogenicity/ tolerance and rapid clearance by the RES could potentially be modified via alterations to the highly immunogenic surface antigens. Repeated use of a phage as a therapeutic, in addition to the interactions with the innate immune system, stimulates memory cells and results in the production of antibodies. However, phage immunological responses may vary, in particular with respect to prior infection with host strains of bacteria, plus different phage strains may mediate different effects on the immune system. The immune response is mostly dose and time dependent; thus experimental conditions in phage therapy trials must be carefully monitored for variations in time, dose, and route of administration as well as presence of adjuvants and other immunogenic agents that all impact tolerance. Given the intimate relationship of phage with human's right from the birth, for phage therapy to develop into a viable clinical alternative, it will require far more rigorous and controlled investigation into host-specific immune responses.

\section{Abbreviations}

APCs: Antigen-presenting cells

CTL: Cytotoxic T lymphocytic

DCs: Dendritic cells

CpG: Deoxycytidylate-phosphate-

deoxyguanylate

IFN- $\gamma$ : Interferon gamma

ILs: Interleukins

Igs: Immunoglobulins

I.m.: Intramuscular

I.p.: Intraperitoneal

I.v.: Intravenous

LPS: Lipopolysaccharide

MDR: Multidrug resistant

NF- $\kappa$ B: Nuclear transcription factor

ODNs: Oligodinucleotides

PAMPs: Pathogen-associated molecular patterns

Pfu: Plaque forming unit

PK: Pharmacokinetics

PD: Pharmacodynamics

PMNs: Polymorphonuclear leukocytes

ROS: Reactive oxygen species

RES: Reticuloendothelial system

SCID: Severe combined immune deficiency

S.c.: $\quad$ Subcutaneous

TLRs: Toll-like receptors

TNF: Tumor necrosis factor.

\section{Authors' Contribution}

T. Kaur and N. Nafissi contributed equally to this work.

\section{Conflict of Interests}

The authors declare that there is no conflict of interests.

\section{References}

[1] F. W. Twort, "Further investigations on the nature of ultramicroscopic viruses and their cultivation," The Journal of Hygiene (London), vol. 36, pp. 204-235, 1936.

[2] F. d'Herelle, "Technique de la recherche du microbe filtrant bactériophage (Bacteriophagum intestinale)," Comptes Rendus des Seances de la Societe de Biologie Paris, vol. 81, pp. 1060-1062, 1918.

[3] F. d'Herelle, "Sur un microbe invisible antagoniste des bacilles dysentériques," Comptes Rendus de l'Académie des Sciences Paris, vol. 165, pp. 373-375, 1917.

[4] J. R. Clark and J. B. March, "Bacteriophages and biotechnology: vaccines, gene therapy and antibacterials," Trends in Biotechnology, vol. 24, no. 5, pp. 212-218, 2006.

[5] J. Alisky, K. Iczkowski, A. Rapoport, and N. Troitsky, "Bacteriophages show promise as antimicrobial agents," Journal of Infection, vol. 36, no. 1, pp. 5-15, 1998.

[6] R. M. Carlton, "Phage therapy: past history and future prospects," Archivum Immunologiae et Therapiae Experimentalis, vol. 47, no. 5, pp. 267-274, 1999.

[7] T. L. Smith, M. L. Pearson, K. R. Wilcox et al., "Emergence of vancomycin resistance in Staphylococcus aureus. Glycopeptide-Intermediate Staphylococcus aureus Working Group," The New England Journal of Medicine, vol. 340, pp. 493-501, 1999.

[8] Y. Taj, F. E. Abdullah, and S. U. Kazmi, "Current pattern of antibiotic resistance in Staphylococcus aureus clinical isolates and the emergence of vancomycin resistance," Journal of the College of Physicians and Surgeons Pakistan, vol. 20, no. 11, pp. 728-732, 2010.

[9] A. Parisien, B. Allain, J. Zhang, R. Mandeville, and C. Q. Lan, "Novel alternatives to antibiotics: bacteriophages, bacterial cell wall hydrolases, and antimicrobial peptides," Journal of Applied Microbiology, vol. 104, no. 1, pp. 1-13, 2008.

[10] S. Matsuzaki, M. Rashel, J. Uchiyama et al., "Bacteriophage therapy: a revitalized therapy against bacterial infectious diseases," Journal of Infection and Chemotherapy, vol. 11, no. 5, pp. 211-219, 2005.

[11] S. Matsuzaki, M. Yasuda, H. Nishikawa et al., "Experimental protection of mice against lethal Staphylococcus aureus infection by novel bacteriophage $\phi \mathrm{MR} 11$," Journal of Infectious Diseases, vol. 187, no. 4, pp. 613-624, 2003.

[12] K. Szczaurska-Nowak, K. Dabrowska, M. Celka et al., "Antitumor effect of combined treatment of mice with cytostatic agents and bacteriophage T4," Anticancer Research, vol. 29, no. 6, pp. 2361-2370, 2009.

[13] B. R. Levin and J. J. Bull, "Population and evolutionary dynamics of phage therapy," Nature Reviews Microbiology, vol. 2, no. 2, pp. 166-173, 2004.

[14] B. Weber-Dabrowska, M. Zimecki, and M. Mulczyk, "Effective phage therapy is associated with normalization of cytokine production by blood cell cultures," Archivum Immunologiae et Therapiae Experimentalis, vol. 48, no. 1, pp. 31-37, 2000. 
[15] T. Wang, G. G. Dsouza, D. Bedi et al., "Enhanced binding and killing of target tumor cells by drug-loaded liposomes modified with tumor-specific phage fusion coat protein," Nanomedicine, vol. 5, no. 4, pp. 563-574, 2010.

[16] M. Sarikaya, C. Tamerler, A. K. Y. Jen, K. Schulten, and F. Baneyx, "Molecular biomimetics: nanotechnology through biology," Nature Materials, vol. 2, no. 9, pp. 577-585, 2003.

[17] A. Sergeeva, M. G. Kolonin, J. J. Molldrem, R. Pasqualini, and W. Arap, "Display technologies: application for the discovery of drug and gene delivery agents," Advanced Drug Delivery Reviews, vol. 58, no. 15, pp. 1622-1654, 2006.

[18] T. Mori, "Cancer-specific ligands identified from screening of peptide-display libraries," Current Pharmaceutical Design, vol. 10, no. 19, pp. 2335-2343, 2004.

[19] L. R. H. Krumpe and T. Mori, "The use of phage-displayed peptide libraries to develop tumor-targeting drugs," International Journal of Peptide Research and Therapeutics, vol. 12, no. 1, pp. 79-91, 2006.

[20] D. Bedi, T. Musacchio, O. A. Fagbohun et al., "Delivery of siRNA into breast cancer cells via phage fusion proteintargeted liposomes," Nanomedicine, vol. 7, no. 3, pp. 315-323, 2011.

[21] C. G. Nicol, L. Denby, O. Lopez-Franco et al., "Use of in vivo phage display to engineer novel adenoviruses for targeted delivery to the cardiac vasculature," FEBS Letters, vol. 583, no. 12, pp. 2100-2107, 2009.

[22] A. Kurzepa, K. Dabrowska, G. Skaradziński, and A. Górski, "Bacteriophage interactions with phagocytes and their potential significance in experimental therapy," Clinical and Experimental Medicine, vol. 9, no. 2, pp. 93-100, 2009.

[23] J. R. Clark and J. B. March, "Bacterial viruses as human vaccines?” Expert Review of Vaccines, vol. 3, no. 4, pp. 463-476, 2004.

[24] J. R. Clark and J. B. March, "Bacteriophage-mediated nucleic acid immunisation," FEMS Immunology and Medical Microbiology, vol. 40, no. 1, pp. 21-26, 2004.

[25] J. B. March, J. R. Clark, and C. D. Jepson, "Genetic immunisation against hepatitis $\mathrm{B}$ using whole bacteriophage $\lambda$ particles," Vaccine, vol. 22, no. 13-14, pp. 1666-1671, 2004.

[26] K. Dabrowska, A. Opolski, J. Wietrzyk et al., "Anticancer activity of bacteriophage T4 and its mutant HAP1 in mouse experimental tumour models," Anticancer Research, vol. 24, no. 6, pp. 3991-3995, 2004.

[27] E. Pajtasz-Piasecka, J. Rossowska, D. Duś, B. WeberDabrowska, A. Zabłocka, and A. Górski, "Bacteriophages support anti-tumor response initiated by DC-based vaccine against murine transplantable colon carcinoma," Immunology Letters, vol. 116, no. 1, pp. 24-32, 2008.

[28] W. Fortuna, R. Międzybrodzki, B. Weber-Dabrowska, and A. Górski, "Bacteriophage therapy in children: facts and prospects," Medical Science Monitor, vol. 14, no. 8, pp. RA126-RA132, 2008.

[29] T. J. M. Molenaar, I. Michon, S. A. M. de Haas, T. J. C. Van Berkel, J. Kuiper, and E. A. L. Biessen, "Uptake and processing of modified bacteriophage M13 in mice: implications for phage display," Virology, vol. 293, no. 1, pp. 182-191, 2002.

[30] S. S. de Almeida, A. A. C. Magalhães, S. C. Soares et al., "The phage display technique: advantages and recent patents," Recent Patents on DNA and Gene Sequences, vol. 5, no. 2, pp. 136-148, 2011.

[31] A. Kurzepa, K. Dabrowska, G. Skaradziński, and A. Górski, "Bacteriophage interactions with phagocytes and their potential significance in experimental therapy," Clinical and Experimental Medicine, vol. 9, no. 2, pp. 93-100, 2009.
[32] H. Bloch, "Experimental investigation on the relationships between bacteriophages and malignant tumors," Archives of Virology, vol. 1, pp. 481-496, 1940.

[33] M. Kantoch and M. Mordarski, "Binding of bacterial viruses by tumor cells in vitro," Postępy Higieny i Medycyny Doświadczalnej, vol. 12, no. 2, pp. 191-192, 1958.

[34] K. Dabrowska, A. Opolski, J. Wietrzyk et al., "Antitumor activity of bacteriophages in murine experimental cancer models caused possibly by inhibition of $\beta 3$ integrin signaling pathway," Acta Virologica, vol. 48, no. 4, pp. 241-248, 2004.

[35] K. Dabrowska, A. Opolski, J. Wietrzyk et al., "Activity of bacteriophages in murine tumor models depends on the route of phage administration," Oncology Research, vol. 15, no. 4, pp. 183-187, 2005.

[36] K. Dabrowska, M. Zembala, J. Boratynski et al., "Hoc protein regulates the biological effects of T4 phage in mammals," Archives of Microbiology, vol. 187, no. 6, pp. 489-498, 2007.

[37] T. Ohtsuki, H. Tsuda, and C. Morimoto, "Good or evil: CD26 and HIV infection,” Journal of Dermatological Science, vol. 22, no. 3, pp. 152-160, 2000.

[38] F. Eriksson, P. Tsagozis, K. Lundberg et al., "Tumor-specific bacteriophages induce tumor destruction through activation of tumor-associated macrophages," Journal of Immunology, vol. 182, no. 5, pp. 3105-3111, 2009.

[39] M. Nishikawa, "Reactive oxygen species in tumor metastasis," Cancer Letters, vol. 266, no. 1, pp. 53-59, 2008.

[40] M. Nishikawa, M. Hashida, and Y. Takakura, "Catalase delivery for inhibiting ROS-mediated tissue injury and tumor metastasis," Advanced Drug Delivery Reviews, vol. 61, no. 4, pp. 319-326, 2009.

[41] A. Przerwa, M. Zimecki, K. Świtała-Jeleń et al., "Effects of bacteriophages on free radical production and phagocytic functions," Medical Microbiology and Immunology, vol. 195, no. 3, pp. 143-150, 2006.

[42] R. Miedzybrodzki, K. Switala-Jelen, W. Fortuna et al., "Bacteriophage preparation inhibition of reactive oxygen species generation by endotoxin-stimulated polymorphonuclear leukocytes," Virus Research, vol. 131, no. 2, pp. 233-242, 2008.

[43] B. Weber-Dabrowska, M. Mulczyk, and A. Gorski, "Bacteriophages as an efficient therapy for antibiotic-resistant septicemia in man," Transplantation Proceedings, vol. 35, no. 4, pp. 1385-1386, 2003.

[44] V. M. Victor, M. Rocha, J. V. Esplugues, and M. De la Fuente, "Role of free radicals in sepsis: antioxidant therapy," Current Pharmaceutical Design, vol. 11, no. 24, pp. 3141-3158, 2005.

[45] J. J. Gill, T. Hollyer, and P. M. Sabour, "Bacteriophages and phage-derived products as antibacterial therapeutics," Expert Opinion on Therapeutic Patents, vol. 17, no. 11, pp. 13411350, 2007.

[46] S. C. Becker, J. Foster-Frey, A. J. Stodola, D. Anacker, and D. M. Donovan, "Differentially conserved staphylococcal SH3b_5 cell wall binding domains confer increased staphylolytic and streptolytic activity to a streptococcal prophage endolysin domain," Gene, vol. 443, no. 1-2, pp. 32-41, 2009.

[47] M. J. Loessner, A. Schneider, and S. Scherer, "Modified Listeria bacteriophage lysin genes (ply) allow efficient overexpression and one-step purification of biochemically active fusion proteins," Applied and Environmental Microbiology, vol. 62, no. 8, pp. 3057-3060, 1996.

[48] J. Varea, B. Monterroso, J. L. Sáiz et al., "Structural and thermodynamic characterization of $\mathrm{Pal}$, a phage natural chimeric lysin active against pneumococci," The Journal of Biological Chemistry, vol. 279, no. 42, pp. 43697-43707, 2004. 
[49] D. Nelson, R. Schuch, P. Chahales, S. Zhu, and V. A. Fischetti, "PlyC: a multimeric bacteriophage lysin," Proceedings of the National Academy of Sciences of the United States of America, vol. 103, no. 28, pp. 10765-10770, 2006.

[50] S. O'Flaherty, R. P. Ross, W. Meaney, G. F. Fitzgerald, M. F. Elbreki, and A. Coffey, "Potential of the Polyvalent antiStaphylococcus bacteriophage K for control of antibioticresistant staphylococci from hospitals," Applied and Environmental Microbiology, vol. 71, no. 4, pp. 1836-1842, 2005.

[51] L. Y. Filatova, S. C. Becker, D. M. Donovan, A. K. Gladilin, and N. L. Klyachko, "LysK, the enzyme lysing Staphylococcus aureus cells: specific kinetic features and approaches towards stabilization," Biochimie, vol. 92, no. 5, pp. 507-513, 2010.

[52] A. Daniel, C. Euler, M. Collin, P. Chahales, K. J. Gorelick, and V. A. Fischetti, "Synergism between a novel chimeric lysin and oxacillin protects against infection by methicillinresistant Staphylococcus aureus," Antimicrobial Agents and Chemotherapy, vol. 54, no. 4, pp. 1603-1612, 2010.

[53] M. Pastagia, C. Euler, P. Chahales, J. Fuentes-Duculan, J. G. Krueger, and V. A. Fischetti, "A novel chimeric lysin shows superiority to mupirocin for skin decolonization of methicillin-resistant and -sensitive Staphylococcus aureus strains," Antimicrobial Agents and Chemotherapy, vol. 55, no. 2, pp. 738-744, 2011.

[54] M. Fenton, R. P. Ross, O. Mcauliffe, J. O’Mahony, and A. Coffey, "Characterization of the staphylococcal bacteriophage lysin CHAP K," Journal of Applied Microbiology, vol. 111, no. 4, pp. 1025-1035, 2011.

[55] A. Letarov and E. Kulikov, "The bacteriophages in humanand animal body-associated microbial communities," Journal of Applied Microbiology, vol. 107, no. 1, pp. 1-13, 2009.

[56] S. R. Gill, M. Pop, R. T. DeBoy et al., "Metagenomic analysis of the human distal gut microbiome," Science, vol. 312, no. 5778, pp. 1355-1359, 2006.

[57] J. L. Sonnenburg, L. T. Angenent, and J. I. Gordon, "Getting a grip on things: how do communities of bacterial symbionts become established in our intestine?" Nature Immunology, vol. 5, no. 6, pp. 569-573, 2004.

[58] A. S. Srivastava, T. Kaido, and E. Carrier, "Immunological factors that affect the in vivo fate of T7 phage in the mouse," Journal of Virological Methods, vol. 115, no. 1, pp. 99-104, 2004.

[59] B. L. Shacklett and P. A. Anton, "HIV infection and gut mucosal immune function: updates on pathogenesis with implications for management and intervention," Current Infectious Disease Reports, vol. 12, no. 1, pp. 19-27, 2010.

[60] R. J. H. Payne and V. A. A. Jansen, "Pharmacokinetic principles of bacteriophage therapy," Clinical Pharmacokinetics, vol. 42, no. 4, pp. 315-325, 2003.

[61] K. Dabrowska, K. Switała-Jelen, A. Opolski, B. WeberDabrowska, and A. Gorski, "A review: bacteriophage penetration in vertebrates," Journal of Applied Microbiology, vol. 98, no. 1, pp. 7-13, 2005.

[62] H. D. Ochs, S. D. Davis, and R. J. Wedgwood, "Immunologic responses to bacteriophage phi-X 174 in immunodeficiency diseases," Journal of Clinical Investigation, vol. 50, no. 12, pp. 2559-2568, 1971.

[63] I. Yacoby, H. Bar, and I. Benhar, "Targeted drug-carrying bacteriophages as antibacterial nanomedicines," Antimicrobial Agents and Chemotherapy, vol. 51, no. 6, pp. 2156-2163, 2007.

[64] S. M. Moghimi, A. C. Hunter, and J. C. Murray, "Nanomedicine: current status and future prospects," FASEB Journal, vol. 19, no. 3, pp. 311-330, 2005.
[65] E. Pajtasz-Piasecka, J. Rossowska, D. Duś, B. WeberDabrowska, A. Zabłocka, and A. Górski, "Bacteriophages support anti-tumor response initiated by DC-based vaccine against murine transplantable colon carcinoma," Immunology Letters, vol. 116, no. 1, pp. 24-32, 2008.

[66] A. Górski, E. Wazna, B. W. Dabrowska, K. Dabrowska, K. Świtała-Jeleń, and R. Międzybrodzki, "Bacteriophage translocation," FEMS Immunology and Medical Microbiology, vol. 46, no. 3, pp. 313-319, 2006.

[67] H. An, C. Qian, and X. Cao, "Regulation of Toll-like receptor signaling in the innate immunity," Science China Life Sciences, vol. 53, no. 1, pp. 34-43, 2010.

[68] L. Diacovich and J. P. Gorvel, "Bacterial manipulation of innate immunity to promote infection," Nature Reviews Microbiology, vol. 8, no. 2, pp. 117-128, 2010.

[69] R. Ostuni, I. Zanoni, and F. Granucci, "Deciphering the complexity of Toll-like receptor signaling," Cellular and Molecular Life Sciences, vol. 67, no. 24, pp. 4109-4134, 2011.

[70] K. Hoshino, O. Takeuchi, T. Kawai et al., "Cutting edge: tolllike receptor 4 (TLR4)-deficient mice are hyporesponsive to lipopolysaccharide evidence for TLR4 as the Lps gene product," Journal of Immunology, vol. 162, no. 7, pp. 3749-3752, 1999.

[71] R. B. Yang, M. R. Mark, A. Gray et al., "Toll-like receptor-2 mediates lipopolysaccharide-induced cellular signalling," Nature, vol. 395, no. 6699, pp. 284-288, 1998.

[72] S. Bauer, C. J. Kirschning, H. Häcker et al., "Human TLR9 confers responsiveness to bacterial DNA via species-specific CpG motif recognition," Proceedings of the National Academy of Sciences of the United States of America, vol. 98, no. 16, pp. 9237-9242, 2001.

[73] A. Rubinstein, Y. Mizrachi, L. Bernstein et al., "Progressive specific immune attrition after primary, secondary and tertiary immunizations with bacteriophage $\phi$ X174 in asymptomatic HIV-1 infected patients," AIDS, vol. 14, no. 4, pp. F55-F62, 2000.

[74] K. L. Elkins, T. R. Rhinehart-Jones, S. Stibitz, J. S. Conover, and D. M. Klinman, "Bacterial DNA containing CpG motifs stimulates lymphocyte-dependent protection of mice against lethal infection with intracellular bacteria," Journal of Immunology, vol. 162, no. 4, pp. 2291-2298, 1999.

[75] K. Heeg and S. Zimmermann, "CpG DNA as a Th1 trigger," International Archives of Allergy and Immunology, vol. 121, no. 2, pp. 87-97, 2000.

[76] A. M. Krieg, "The role of CpG motifs in innate immunity," Current Opinion in Immunology, vol. 12, no. 1, pp. 35-43, 2000.

[77] M. R. Geier, M. E. Trigg, and C. R. Merril, "Fate of bacteriophage lambda in non immune germ free mice," Nature, vol. 246, no. 5430, pp. 221-223, 1973.

[78] C. R. Merril, B. Biswas, R. Carlton et al., "Long-circulating bacteriophage as antibacterial agents," Proceedings of the National Academy of Sciences of the United States of America, vol. 93, no. 8, pp. 3188-3192, 1996.

[79] C. J. Inchley, "The actvity of mouse Kupffer cells following intravenous injection of T4 bacteriophage," Clinical and Experimental Immunology, vol. 5, no. 1, pp. 173-187, 1969.

[80] C. J. Inchley and J. G. Howard, "The immunogenicity of phagocytosed T4 bacteriophage: cell replacement studies with splenectomized and irradiated mice," Clinical and Experimental Immunology, vol. 5, no. 1, pp. 189-198, 1969.

[81] J. W. Uhr and G. Weissman, "Intracellular distribution and degradation of bacteriophage in mammalian tissues," The Journal of Immunology, vol. 94, pp. 544-550, 1965. 
[82] A. E. Nelstrop, G. Taylor, and P. Collard, "Studies on phagocytosis. II. In vitro phagocytosis by macrophages," Immunology, vol. 14, no. 3, pp. 339-346, 1968.

[83] C. R. Merril, D. Scholl, and S. L. Adhya, "The prospect for bacteriophage therapy in Western medicine," Nature Reviews Drug Discovery, vol. 2, no. 6, pp. 489-497, 2003.

[84] A. M. Cuesta, E. Suarez, M. Larsen et al., "Enhancement of DNA vaccine potency through linkage of antigen to filamentous bacteriophage coat protein III domain I," Immunology, vol. 117 , no. 4 , pp. 502-506, 2006.

[85] R. Barfoot, S. Denham, L. A. Gyure et al., "Some properties of dendritic macrophages from peripheral lymph," Immunology, vol. 68, no. 2, pp. 233-239, 1989.

[86] A. V. Sokoloff, I. Bock, G. Zhang, M. G. Sebestyén, and J. A. Wolff, "The interactions of peptides with the innate immune system studied with use of T7 phage peptide display," Molecular Therapy, vol. 2, no. 2, pp. 131-139, 2000.

[87] R. Miedzybrodzki, W. Fortuna, B. Weber-Dabrowska, and A. Gorski, "A retrospective analysis of changes in inflammatory markers in patients treated with bacterial viruses," Clinical and Experimental Medicine, vol. 9, no. 4, pp. 303-312, 2009.

[88] K. P. Kim, J. D. Cha, E. H. Jang et al., "PEGylation of bacteriophages increases blood circulation time and reduces T-helper type 1 immune response," Microbial Biotechnology, vol. 1, no. 3, pp. 247-257, 2008.

[89] M. A. Croyle, N. Chirmule, Y. Zhang, and J. M. Wilson, "PEGylation of E1-deleted adenovirus vectors allows significant gene expression on readministration to liver," Human Gene Therapy, vol. 13, no. 15, pp. 1887-1900, 2002.

[90] J. Zhang, X. Xiao, W. Liu, G. Demirci, and X. C. Li, "Inhibitory receptors of the immune system: functions and therapeutic implications," Cellular and Molecular Immunology, vol. 6, no. 6, pp. 407-414, 2009.

[91] M. C. Carroll, "The complement system in regulation of adaptive immunity," Nature Immunology, vol. 5, no. 10, pp. 981-986, 2004.

[92] D. T. Fearon, "The complement system and adaptive immunity," Seminars in Immunology, vol. 10, no. 5, pp. 355-361, 1998.

[93] B. J. C. Janssen and P. Gros, "Structural insights into the central complement component C3," Molecular Immunology, vol. 44, no. 1-3, pp. 3-10, 2007.

[94] R. J. Wedgwood, H. D. Ochs, and S. D. Davis, "The recognition and classification of immunodeficiency diseases with bacteriophage phiX 174," Birth Defects, vol. 11, no. 1, pp. 331-338, 1975.

[95] H. D. Ochs, R. H. Buckley, R. H. Kobayashi et al., "Antibody responses to bacteriophage $\phi \mathrm{X} 174$ in patients with adenosine deaminase deficiency," Blood, vol. 80, no. 5, pp. 1163-1171, 1992.

[96] K. Seyama, S. Nonoyama, I. Gangsaas et al., "Mutations of the CD40 ligand gene and its effect on CD40 ligand expression in patients with X-linked hyper IgM syndrome," Blood, vol. 92, no. 7, pp. 2421-2434, 1998.

[97] S. Nonoyama, A. Etzioni, H. Toru et al., "Diminished expression of CD40 ligand may contribute to the defective humoral immunity in patients with MHC class II deficiency," European Journal of Immunology, vol. 28, no. 2, pp. 589-598, 1998.

[98] L. J. Bernstein, H. D. Ochs, R. J. Wedgwood, and A. Rubinstein, "Defective humoral immunity in pediatric acquired immune deficiency syndrome," Journal of Pediatrics, vol. 107, no. 3, pp. 352-357, 1985.
[99] H. D. Ochs, A. K. Junker, A. C. Collier, F. S. Virant, H. H. Handsfield, and R. J. Wedgwood, "Abnormal antibody responses in patients with persistent generalized lymphadenopathy," Journal of Clinical Immunology, vol. 8, no. 1, pp. 57-63, 1988.

[100] I. R. Cohen and L. C. Norins, "Antibiodies of the IgG, IgM, and IgA classes in newborn and adult sera reactive with gram-negative bacteria," Journal of Clinical Investigation, vol. 47, no. 5, pp. 1053-1062, 1968.

[101] I. Fogelman, V. Davey, H. D. Ochs et al., "Evaluation of CD4+ T cell function in vivo in HIV-infected patients as measured by bacteriophage phiX174 immunization," Journal of Infectious Diseases, vol. 182, no. 2, pp. 435-441, 2000.

[102] W. T. Shearer, D. J. Lugg, H. M. Rosenblatt et al., "Antibody responses to bacteriophage $\phi \mathrm{X}-174$ in human subjects exposed to the Antarctic winter-over model of spaceflight," Journal of Allergy and Clinical Immunology, vol. 107, no. 1, pp. 160-164, 2001.

[103] S. A. Hedstrom and C. Kamme, "Antibodies against staphylococcal bacteriophages in human sera. II. Assay of antibodies in exacerbation and regression of chronic staphylococcal osteomyelitis," Acta Pathologica et Microbiologica Scandinavica-Section B, vol. 81, no. 6, pp. 749-752, 1973.

[104] C. Kamme, "Antibodies against staphylococcal bacteriophages in human sera. I. Assay of antibodies in healthy individuals and in patients with staphylococcal infections," Acta Pathologica et Microbiologica Scandinavica-Section B, vol. 81, no. 6, pp. 741-748, 1973.

[105] A. Synnott, K. Ohshima, Y. Nakai, and Y. Tanji, "IgA response of BALB/c mice to orally administered Salmonella typhimurium flagellin-displaying T2 bacteriophages," Biotechnology Progress, vol. 25, no. 2, pp. 552-558, 2009. 

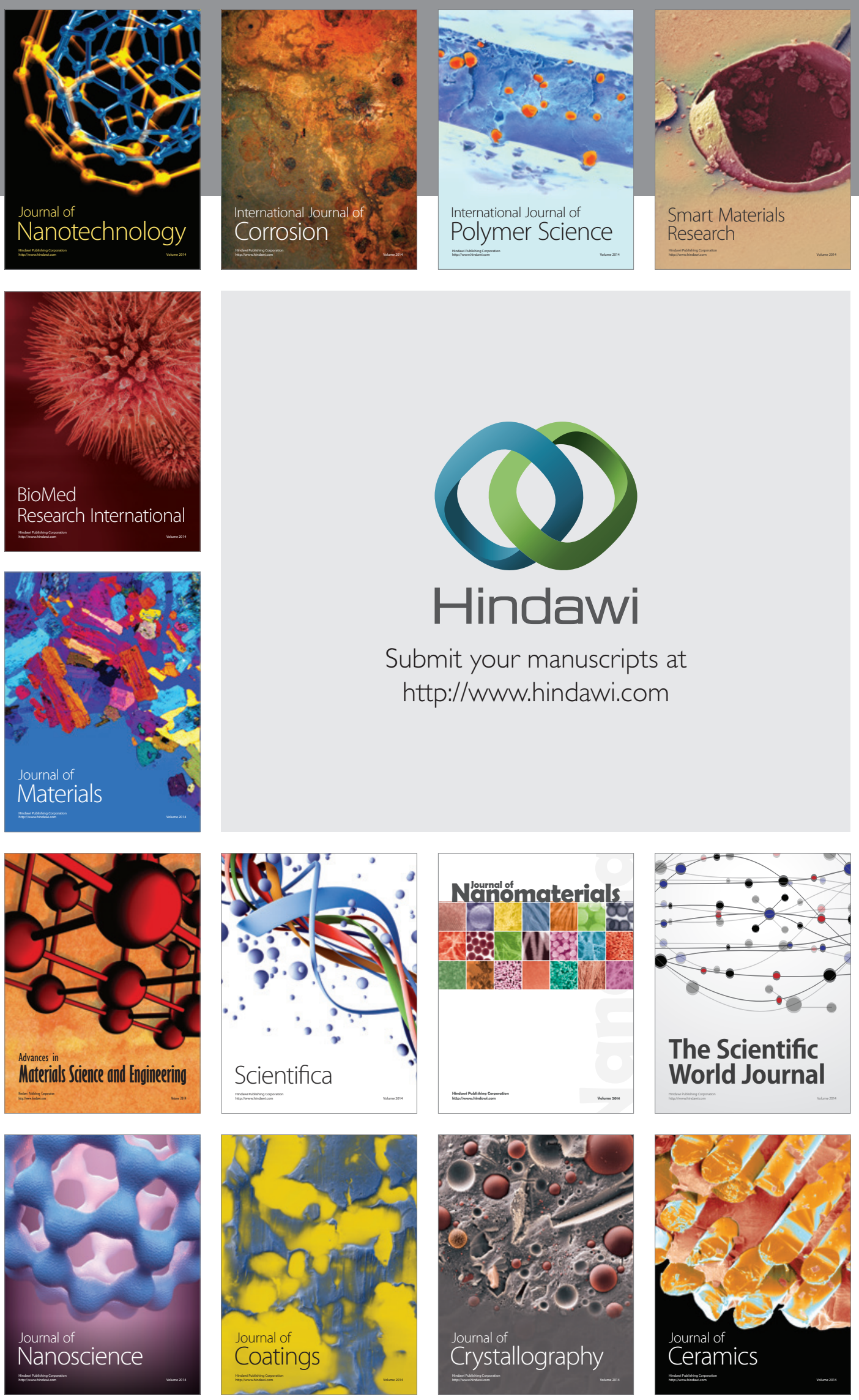

The Scientific World Journal

Submit your manuscripts at

http://www.hindawi.com

\section{World Journal}

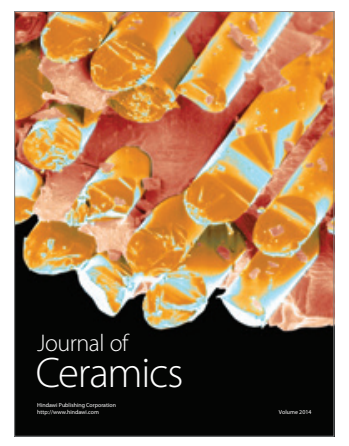

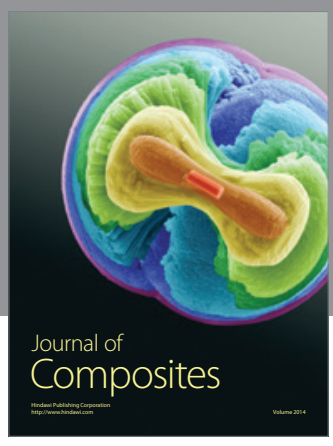
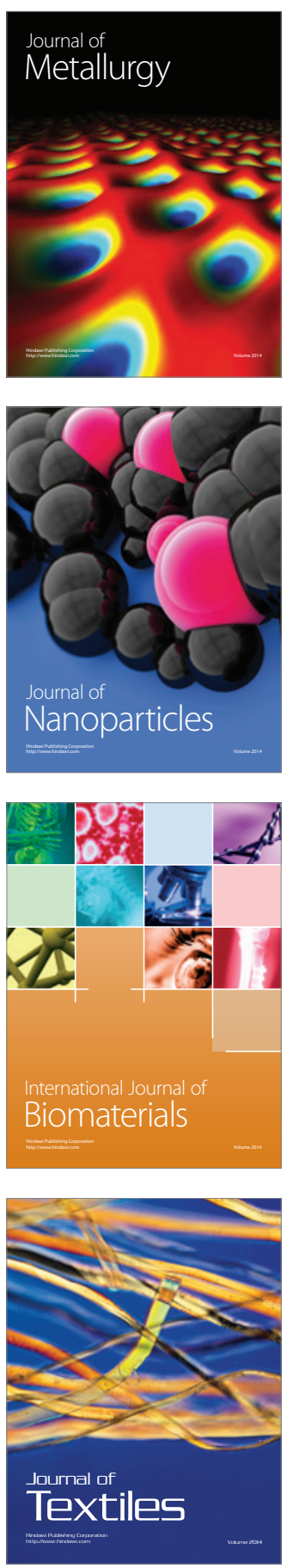